\title{
Should we use popular brands to promote healthy eating among children?
}

\author{
Ingibjorg Gunnarsdottir ${ }^{1,2, *}$ and Inga Thorsdottir ${ }^{1,2}$ \\ 'Unit for Nutrition Research, University of Iceland and Landspitali University Hospital, Eiriksgata 29, \\ 101 Reykjavik, Iceland: ${ }^{2}$ Faculty of Food Science and Nutrition, School of Health Sciences, \\ University of Iceland, Vatnsmyrarvegur 16, 101 Reykjavik, Iceland
}

Submitted 19 August 2009: Accepted 16 March 2010: First published online 4 May 2010

\begin{abstract}
Objective: Studies indicate that food and beverages typically marketed to children are products high in fat, sugar and salt. LazyTown is an entertainment brand with a focus on healthy lifestyle, aimed at making health education entertaining. The aim of the present study was to assess whether children perceive food to taste better with a LazyTown label on the wrapping compared with the original packaging.

Design: Five pairs of identical food and beverage samples were introduced. We aimed to select healthy food and beverages from various food groups. Preference for the LazyTown food was coded as +1 , no preference 0 and preference for the original food as -1 . An average 'preference score' was calculated for each subject by adding up the answers.

Setting: Three pre-schools in the Greater Reykjavik area, Iceland.

Subjects: Subjects were pre-school children aged 3.5 to 6 years ( $n$ 66).

Results: Most children answered correctly that there was no difference in the taste between the two identical food samples. However, between 27 and $42 \%$ (depending on the product) of children preferred the taste of LazyTown food and beverages despite the fact that the test food was identical. The mean preference score was $0 \cdot 29$ (SD $0 \cdot 32$, median $0 \cdot 20,95 \%$ CI $0 \cdot 21,0 \cdot 38$ ).

Conclusions: Our findings add to past research by demonstrating children's preferences for child-oriented wrappings rather than regular wrapping. It might be suggested that popular brands could be useful to promote healthy eating among young children along with other actions.
\end{abstract}

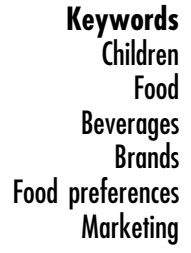

Food and beverage marketing to children and their families is known to influence their preferences and choices $^{(1,2)}$. By 2 years of age, most children can recognize products in supermarkets and ask for them by name $^{(2)}$. Several different techniques have been used to appeal to children, including branded spokescharacters and licensed characters. However, these have not been used to market healthful food and beverage products until recently $^{(2)}$. Up to $89 \%$ of foods specifically targeted at children can be classified as of poor nutritional quality $^{(3)}$, i.e. food that is often high in sugar, fat and energy. In 2006 the US Institute of Medicine (IOM) reported results from a systematic review on food marketing for children and youth ${ }^{(2)}$. In its conclusion the IOM establishes that there is a need and an opportunity to turn food and beverage marketing focuses toward better diets for American children and youth, adding that this will not be a small task. This task is also prioritized in the EU Consumer Policy Strategy 2007-2013 ${ }^{(4)}$.
It is likely that the marketing of popular brands to encourage consumption among children will continue, unless some kind of legislation is introduced to prohibit it. In 2007 a study showed that children think food tastes better in McDonalds wraps than in white wraps ${ }^{(5)}$. Although the results were not surprising they are shocking, and emphasize the power of marketing and branding. Ronald McDonald is a well-known spokescharacter, created in 1963 to appeal to children and promote food offered at McDonalds ${ }^{(2)}$. The question is whether the powerful tool of marketing (e.g. through popular brands, spokescharacters or licensed characters) is likely to be successful to introduce or stimulate consumption of healthy food among young children.

LazyTown is an Icelandic children's television programme now airing in more than 100 countries. LazyTown is an entertainment brand with a focus on healthy lifestyle, aimed at making health education entertaining ${ }^{(6)}$. The stars of the show are Sportacus and Stephanie, introducing 
'SportCandy' (fruits and vegetables) and physical activity to children. We conducted a pilot study assessing whether children perceive food to taste better with a LazyTown label on the wrapping compared with the original packaging. The hypothesis was that children will prefer the taste of foods they perceive to be from LazyTown.

\section{Subjects and methods}

We used similar methodology as introduced by Robinson's group at Stanford University, showing that food tastes better in McDonalds wraps than in white wraps ${ }^{(5)}$. However, we chose to use the original wraps for comparison instead of white ones as children tend to be apprehensive to try unfamiliar foods ${ }^{(7)}$ and white wraps were therefore prone to cause bias. The present study was reported to the Data Protection Authority (S3608) and permission was gathered from the appropriate authorities and headmasters of the pre-schools involved. A written consent was signed by parents of the subjects. The study was conducted in three pre-schools in the Greater Reykjavik area where sixty-six pre-school children, aged 3.5 to 6 years, completed the study. To ensure no effects from the researcher, one research assistant sat behind a screen and could not see the child, but his arms could reach

Table 1 Social background of the subjects (parents' education and marital status, number of siblings living in the household): preschool children aged 3.5 to 6 years ( $n 66$ ), Greater Reykjavik area, Iceland

\begin{tabular}{lrr}
\hline & $n$ & $\%$ \\
\hline Mother's education & & \\
$\quad$ Secondary school (<11 years) & 4 & $7 \cdot 8$ \\
Gymnasium (13-14 years) & 16 & $31 \cdot 4$ \\
University level ( $>15$ years) & 31 & $60 \cdot 8$ \\
Father's education & 3 & $6 \cdot 8$ \\
$\quad$ Secondary school (<11 years) & 19 & $43 \cdot 2$ \\
Gymnasium (13-14 years) & 22 & $50 \cdot 0$ \\
$\quad$ University level ( $>15$ years) & 44 & $86 \cdot 3$ \\
Marital status & 7 & $13 \cdot 7$ \\
$\quad$ Married or partnership & & \\
Not in relationship & 7 & 13.5 \\
Number of siblings living in the subject's household & 44 & $84 \cdot 6$ \\
One & 1 & 1.9 \\
Two & & \\
Three & & \\
\hline
\end{tabular}

around the screen to introduce the products tasted. Another research assistant was placed behind the child. Five pairs of identical food and beverages were introduced one at the time. The selection of food was somewhat arbitrary (see Table 2 below), but we aimed at choosing healthy food and beverages from various food groups. Inclusion of water into a study assessing taste preference might seem odd as water is tasteless. Given the young age of the children, we did not want to include a flavoured drink in this pilot study as many of them contain sugar or acid that could have negative effects on dental health. The children were asked to point out the LazyTown food (identified by all subjects) and then the child was asked to taste the two samples (random order). The blinded research assistant then raised the question: 'Tell me if they taste the same, or point to the food/drink that tastes the best to you?' The research assistant placed behind the child recorded the answers which were coded. Preference for the LazyTown food was coded as +1 , no preference 0 and preference for the original food as -1 . An average 'preference score' was calculated for each subject by adding up the answers.

\section{Results}

The social background of the subjects is shown in Table 1. The social background questionnaire, including questions on attitudes towards LazyTown, was returned by fifty-one parents (77\%). Information about the educational level of fathers was available for forty-four subjects (67\%), i.e. excluding fathers not living together with the mother. The average age of the children's mothers and fathers was $36 \cdot 2$ (SD $5 \cdot 3$ ) years and $37 \cdot 3$ (SD $6 \cdot 1$ ) years, respectively.

Table 2 demonstrates the results of the taste preference study. Most children answered correctly that there was no difference in taste between the two identical food samples. However, between 27 and $42 \%$ (depending on the product) of children preferred the taste of LazyTown food and beverages despite the fact that the test food was identical. The mean preference score was $0 \cdot 29$ (SD $0 \cdot 32$, median $0 \cdot 20,95 \%$ CI $0 \cdot 21,0 \cdot 38$ ). As shown in Table 2 , $42 \%$ of the children claimed that the LazyTown bread tasted better than the one in original wrappings. The

Table 2 Taste preferences: pre-school children aged 3.5 to 6 years $(n 66)$, Greater Reykjavik area, Iceland

\begin{tabular}{|c|c|c|c|c|c|c|}
\hline \multirow[b]{2}{*}{ Sample } & \multicolumn{2}{|c|}{ Preference for sample in original wrappings } & \multicolumn{2}{|c|}{ Taste the same or no answer } & \multicolumn{2}{|c|}{ Preference for sample in LazyTown wrappings } \\
\hline & $n$ & $\%$ & $n$ & $\%$ & $n$ & $\%$ \\
\hline Water & 3 & $4 \cdot 5$ & 45 & $68 \cdot 2$ & 18 & $27 \cdot 3$ \\
\hline Bread & 5 & $7 \cdot 8$ & 32 & $50 \cdot 0$ & 27 & $42 \cdot 2$ \\
\hline Fruit juice & 4 & $6 \cdot 3$ & 36 & $56 \cdot 3$ & 24 & $37 \cdot 4$ \\
\hline Yoghurt & 3 & $4 \cdot 8$ & 43 & $68 \cdot 3$ & 17 & $27 \cdot 0$ \\
\hline Carrots & 2 & $3 \cdot 1$ & 35 & $54 \cdot 7$ & 27 & $42 \cdot 2$ \\
\hline
\end{tabular}

Two children did not want to taste the bread, juice and carrots and one child did not want to taste the yoghurt. Their answers were coded as 0 when calculating the preference score. 
Table 3 Attitudes towards LazyTown: parents of pre-school children aged 3.5 to 6 years ( $n 66$ ), Greater Reykjavik area, Iceland

\begin{tabular}{lrr}
\hline & $n$ & $\%$ \\
\hline Attitude towards LazyTown & & \\
Very positive & 21 & $41 \cdot 2$ \\
Rather positive & 23 & $45 \cdot 1$ \\
Neither positive nor negative & 5 & $9 \cdot 8$ \\
Rather negative & 2 & $3 \cdot 9$ \\
Very negative & 0 & $0 \cdot 0$ \\
Attitude towards marketing of healthy food & & \\
for children using the LazyTown brand & & \\
Very positive & 19 & $37 \cdot 3$ \\
Rather positive & 16 & $31 \cdot 4$ \\
Neither positive nor negative & 14 & $27 \cdot 4$ \\
Rather negative & 2 & $3 \cdot 9$ \\
Very negative & 0 & $0 \cdot 0$ \\
\hline
\end{tabular}

bread we used was rich in fibre $(8 \mathrm{~g} / 100 \mathrm{~g}$ bread) but Icelandic children are used to breads that have only half this amount of dietary fibre per $100 \mathrm{~g}$ bread.

Parents and caregivers answered a short questionnaire about attitude towards LazyTown and if the child was using any products related to LazyTown (Table 3). All of the parents involved knew LazyTown and 90\% of the children who participated in the study did own some products related to LazyTown. Examples of products owned by the children were LazyTown clothes, shoes, books, DVDs and costumes, among other things. Ninetyeight per cent of the parents claimed that their children watched or listened to LazyTown entertainment (radio, television or DVD) for an average duration of $1 \cdot 1(\mathrm{SD} 1 \cdot 1)$ $\mathrm{h} /$ week. Taste preference was not related to parent's education, marital status, the number of siblings or attitudes towards LazyTown.

\section{Discussion}

Foods that are considered to be healthy, such as fruits, vegetables and food rich in dietary fibre, are seldom marketed to children. Intake of fruits and vegetables is less than half of the recommended amount in the diet of Icelandic children and the intake of dietary fibre is relatively low ${ }^{(8)}$. Promoting and introducing healthy food is a huge challenge which demands collaboration between nutritionists, public health experts, the food industry and marketing specialists. Several different approaches should be considered aimed at increasing children's consumption of fruits, vegetables and other healthy foods.

Although the majority of the pre-school children participating in the present study correctly did not observe any difference in taste between the two identical food samples, around 30\% preferred the taste of LazyTown food and beverages. Although the results might not solely be related to the brand, the study clearly demonstrates children's preferences for child-oriented wrappings rather than regular wrapping. Further studies are needed to distinguish between the effects of a simple child-oriented wrapping $v$. a popular brand such as LazyTown. In the present study we used samples of food considered to be healthy. The bread used in the study was twice as rich in fibre as the bread Icelandic children consume most often $^{(8)}$. One might suggest that the introduction of healthy food for children might be easier using childoriented wrappings. However, this pilot study only provides part of the information needed to make such an assumption, and further studies are encouraged.

Although the educational status of parents and their attitude towards the brand involved were not found to be associated with taste preference in the present study, these factors should be taken into consideration when interpreting the results. About 50-60\% of parents involved in our study had a university degree compared with about $38 \%$ in the general population in the Greater Reykjavik area and about $21 \%$ in rural Iceland ${ }^{(9)}$. The sample is therefore not representative for the general population in Iceland. Furthermore, the attitude of more than $85 \%$ of parents was rather or very positive towards the brand involved. The parents' attitude is likely to be mirrored in the children's attitude, which in turn might have affected the results of the present study.

The limited funding sources in the public health sector make it difficult to fight the power of marketing. Fast-food logos such as McDonalds and Burger King are recognized by $89 \%$ and $86 \%$ of US children, showing that these companies might engage children's attention which in turn might influence their parents' purchasing behaviour $^{(10)}$. Encouraging private companies to use popular brands, child-oriented licensed cartoons or other real-life spokescharacters to introduce healthy food or repackage regular healthy food to appeal to children might be considered as a public health approach ${ }^{(2)}$. One way of moving food and beverage marketing towards healthier choices might be by legislation regarding the nutrient profile of food targeted to children and youth, aimed at lowering sugar, salt and saturated fat in the diet ${ }^{(11)}$.

Although LazyTown is an entertainment brand with a focus on healthy lifestyle, it should be noted that it is a children's television programme. Recognition of the brand, dedicated to children's health, is therefore mainly related to television viewing. Food and beverages targeted to children are commonly introduced through television commercials. It is known that the introduction of products to young children can in turn affect their future food preferences ${ }^{(12)}$. According to the IOM report approximately half of all commercials during children's television programming consist of branded high-energy and low-nutrient foods and beverages ${ }^{(2)}$. Recently Icelandic authorities prohibited advertisements during children's television programming. The attainment of this action has not been evaluated but might possibly have favourable effects with respect to public health nutrition, and decrease childhood obesity ${ }^{(13)}$. However, other means 
of marketing, for example Internet food marketing, might become a larger problem in the future ${ }^{(14,15)}$.

In conclusion, our findings add to past research by demonstrating children's preferences for child-oriented wrappings rather than regular wrappings. It might be suggested that popular brands could be useful to promote healthy eating among young children along with other actions.

\section{Acknowledgements}

The study was supported by The Technological Development and Innovation Fund hosted by Rannís - The Icelandic Centre for Research. LazyTown labels (to cover the original wrappings) were provided by LazyTown. Bread was provided by Myllan, yoghurt by Mjolka, carrots by Hollt\&Gott and fruit juice (smoothie) by Froosh, who also provided bottles for the water (tap water). The authors have no conflicts of interest; neither they nor their institutes will profit from sales of LazyTown products. Both authors contributed to the design, data collection and handling, as well as writing the paper. We wish to thank Tinna Eysteinsdottir, Bryndis Elfa Gunnarsdottir and Gudrun Kristin Sigurgeirsdottir for their help during the course of the study.

\section{References}

1. Nestle M (2006) Food industry and health: mostly promises, little action. Lancet 368, 564-565.

2. Institute of Medicine, Committee on Food Marketing and the Diets of Children and Youth (2006) Food Marketing to Children and Youth: Threat or Opportunity? Washington, DC: The National Academies Press.
3. Elliott C (2008) Assessing 'fun foods': nutritional content and analysis of supermarket foods targeted at children. Obes Rev 9, 368-377.

4. Commission of the European Communities (2007) EU Consumer Policy Strategy 2007-2013. Communication from the Commission to the Council, the European Parliament and the European Economic and Social Committee. Brussels: Commission of the European Communities; available at http://ec.europa.eu/consumers/overview/cons_ policy/doc/EN_99.pdf

5. Robinson TN, Borzekowski DLG, Matheson DM et al. (2007) Effects of fast food branding on children's taste preferences. Arch Pediatr Adolesc Med 161, 792-797.

6. LazyTown Entertainment (2009) Corporate information. http://www.lazytown.com/articles.aspx?file $=30122008094955$ / (accessed July 2009).

7. Fallon AE, Rozin P \& Pliner P (1984) The child's conception of food: the development of food rejections with special reference to disgust and contamination sensitivity. Child Dev 55, 566-575.

8. Kristjansdottir AG \& Thorsdottir I (2009) Adherence to food-based dietary guidelines and evaluation of nutrient intake in 7-year-old children. Public Health Nutr 12, 1999-2008.

9. Statistics Iceland (2009) Statistical Yearbook of Iceland 2009. Wages, Income and Labour Market. Reykjavik: Statistics Iceland.

10. Arredondo E, Castaneda D, Elder JP et al. (2009) Brand name $\log$ recognition of fast food and healthy food among children. J Community Health 34, 73-78.

11. Lobstein $\mathrm{T} \&$ \& Davies S (2009) Defining and labelling 'healthy' and 'unhealthy' food. Public Health Nutr 12, 331-340.

12. Mennella JA \& Beauchamp GK (1998) Early flavor experiences: research update. Nutr Rev 56, 205-211.

13. Veerman JL, Van Beeck EF, Barendregt JJ et al. (2009) By how much would limiting TV food advertising reduce childhood obesity? Eur J Public Health 19, 365-369.

14. Kelly B, Bochynska K, Kornman K et al. (2008) Internet food marketing on popular children's websites and food product websites in Australia. Public Health Nutr 11, 1180-1187.

15. Yngve A (2007) Food and drink marketing to children: a continuing scandal. Public Health Nutr 10, 971-972. 